use ; the second pair adapt him to a distance of 25 centimetres, approximately that at which the objects are viewed in the mirrors. The lenses in the latter pair of glasses are decentred inwards. Stereoscopic training is at once resorted to when the glasses are procured. The patient's mother is first shown the use of the instrament. The child is then shown the two separate halves of the figure on the slides. The latter are then superposed and he sees the whole figure and is told he must look for it in the mirrors. He is now placed on a chair facing the windows and the teacher stands behind holding the angle of the mirror in front of the patient's nose and open at about a right angle. 'The head is steadied by the teacher's wrists in this position. If the patient sees the separate halves of the object simultaneously the mirrors are gently manipulated until he fuses them and I find that if left alone with the mother the child can often accomplish this sooner than with anyone else. The next step is to train him to relax his convergence in the interests of binocular vision and this is often a tedious business, but steady improvement usually takes place if he is exercised twice daily by the mother and presents himself every fortnight at the hospital. Herein lies, I think, the chief argument for the use of a stereoscope at home. The fusion faculty in a young child may be readily aroused and preserved by occasional exercises, but to orercome the tendency to converge unduly requires many such exercises and these at short intervals. In the cases where the patient is unable to see both objects simultaneously in the mirrors, the one seen may be thrown into shade by tilting the mirror, and the stay on the opposite side being gently released from its attachment the bar may be moved independently to attract attention.

With regard to the age at which such exercises may be begun there is no definite rule, much depending on the idiosyncracy of the child. Glasses should be ordered, however, and stereoscopic training should be resorted to at the earliest age possible in each individual case. Other methods of orthoptic training, such as bar reading, are most useful with older children, but cannot contend in point of accuracy with the stereoscope. I would point out, however, the advantage of teaching a child its letters at the earliest age possible, as a modified form of bar reading can then be adopted with large letters and is of the greatest value. In cases of monocular squint I cover the good eye until the squint becomes alternating at the will of the patient, though in such a case the visual acuity in one eye may remain much below that of the other. In such a case stereoscopic training should also be adopted as a modified though useful form of binocular vision may be procured even though the sight of one eye differs greatly from the other. I do not believe, however, in the prolonged exclusion of one eye after a fair effort has been made to restore the visual acuity of the other, nor do I think that such wearisome treatment renders the patient more likely to learn to fuse in the stereoscope. With regard to the question of operation tenotomy of an internal rectus is necessary in most old cases of monocular squint and probably in these alone. Advancement of each external rectus has now many advocates and is far preferable in the younger cases. The earlier stereoscopic training is resorted to, the greater the care taken in its details, and the more constant its employment the less frequently will the surgeon have to resort to operative treatment in cases of convergent squint.

Wimpole-street, W.

\section{CHRONIC SPHENOIDAL SUPPURATION : SOME OBSERVATIONS ON OPERATION AND CICATRISATION.}

BY DAVID MCKEOWN, M.A., M.D., M.CH. R.U.I., SURGEON TO THE MANCHESTER EYE AND EAR HOSPITAL.

THE treatment of chronic suppuration of the sphenoidal sinus ranges itself under three heads: (1) irrigation and insufflation of powders; (2) breaking down the anterior wall and curetting the cavity ; and (3) extending the operation by removing a part of the floor.

Some surgeons advise against operation on account of its difficulties and dangers. The depth of the sinus from the suiface, the small and uneven calibre of the channel for manipulation, the irregularity of contour of the cavity which may present large pouches or diverticuli, the important intracranial structures in close relationship with it, and the breaches (anatomical or pathological) which may be found in the bony wall-all lend countenance ta this view. But an unyielding abscess cavity (bony walls) filled with retained pathological products (solid and fluid) and the lining membrane of which has suffered the usual degenerative changes cannot be cured by irrigation through an opening at a considerable height above the floor. Hence the attempt to treat the sinus on the lines which surgical experience has shown to be essentialremoval of pathological products and drainage. This end was sought by breaking down the anterior wall and curetting the cavity. Did the means attain the end ? Concerning the removal of the pathological products it is to be observed, having regard to the anatomical conditions and to the pathological changes which may have taken place, that curetting must be considered as a delicate procedure and that in individual instances there may be doubt as to whether it has been efficient-whether the diverticula and pouches have been thoroughly explored. In respect of the drainage effected the method of operation was also open to objection. The opening obtained does not always reach the level of the lowest part of the sinus. 'To remedy this defect it was sug. gested that a part of the floor should be removed. Does the enlarged operation always secure thorough drainage? I have performed it in three cases, removing (in addition to the whole of the anterior wall) as much as I could-both antero. posteriorly and laterally - of the floor. I employed Grunwald's forceps and burrs driven by a dental engine. 'The burrs were very useful, enabling portions of bone to be removed which on account of physical difficulties could not be dealt with by the forceps. In two of the cases (mentioned hereafter as No. 2 and No. 3) the opening effected almost reached the level of the lowest point of the floor, but in the patient mentioned hereafter as No. 1 it did not, altbough the opening was large, the great depth and a rapidly increasing thickness of the bony floor limiting the operation. In all the cases the lateral margins of the opening were flush with the septum and the outer wall. Whether or not the drainage in such cases is effectual depends not merely on the presence or absence of depressions or pouches but also largely on the character of the healing process which sets in. 'This suggests the question, What is the condition of the sinus when as the result of treatment it has ceased to be a discharging cavity? Has it become lined by a more or less thin dry membrane or has it become wholly or largely occupied by granulation tissue? Even where the opening has been the largest possible the surgeon would probably find it a difficult matter to describe the condition of the cavity at a given moment during cicatrisation.

As the cases which I have mentioned bear upon the points which have been raised I shall now state a few facts concerning them. The patients were a man, aged 30 years, and two young women, aged 21 and 19 years respectively. In all (left side) there were nasal polypi (in No. 1 and No. 3 these were so numerous and bulky as to fill a nostril of large dimensions- the septum was displaced-and also to encroach on the post-nasal space); in all the ethmoidal cells and the sphenoidal sinus were involved; in all the middle turbinated bone and the polypi were removed, the ethmoidal cells were broken down and curetted, and then the anterior wall of the sphenoidal sinus was removed and the cavity curetted. In No. 1 and No. 3 the floor of the sinus was not removed for several weeks, but in No. 2 the anterior wall and the floor were removed at the same sitting. I was forced to remove the floor in No. 1 by finding on one occasion that the quantity of secretion on dressing was greater than could be accommodated in the cavity as revealed by exploration after removal of the anterior wall. From this circumstance it was inferred that there must be a pouch so situated as to escape detection and necessitating for exploration and treatment a larger opening. This view was found to be correct when the larger part of the floor was removed. It was then seen that there was a large deep pouch, lateral to the plane of the outer wall of the nose, formed by a bony septum which was beyond the effective reach of the forceps and burr, so that for the pouch I was limited to scraping by a ring knife. In all the cases the ethmoidal seat of operation healed quickly and satisfactorily; in all granulation tissue was formed in such quantity in the sinus and arcund its artificial opening that, large as the aperture was, it became 
so reduced both antero-posteriorly and laterally that $I$ thought it insufficient for drainage and dressing and likely to close. Hence, on several occasions I have by the cautery enlarged the opening almost to its greatest dimensions and destroyed part of the granulation tissue (in one of the cases I have also used chromic acid).

In all the cases the discharge is now small in quantity : but can one be sure that none is penned up either in anatomical pockets or cicatricial pockets-i.e., pockets formed by the coalescence or contact of opposing granulations leaving cavities behind unlined by dry membrane? Judging from what takes place in other more accessible parts of the budy such an occurrence must be regarded as not improbable. My experience of radical mastoid operations-extending to about $200-$ shows this clearly. Here the field of operation lies before the eye, pathological products can as a rule be completely removed, and the wound cavity in its entirety and throughout cicatrisation is generally open to inspection. In some cases the cicatricial tissue produced is small, so small, indeed, that the healed cavity is almost as large as the operation cavity which has been covered by a thin layer of dry membrane. In other cases the cicatrised cavity is small, very much smaller than the operation cavity, granulation tissue having been abundantly produced. Between these extremes there are many grades. The free production of granulation tissue after mastoid operations leads at times to trouble. Cases are not unusual in which it is difficult to keep opposing surfaces apart until the reparative process immediately behind (deeper) has been effected-in other words, to prevent the formation of pockets. This difficulty I have experienced in cases where at the time of operation I have paid special attention to the walls of the cavity with a view to guard against this contingency by so far as possible removing ridges and avoiding depressions. Again, pockets may be in existence for considerable periods without manifesting their presence; in one case a pocket requiring treatment was found after months of what seemed complete cicatrisation. In studying sphenoidal cicatrisation our experience of mastoid cicatrisation should not be forgotten, neither should it be overlooked that the latter is more under the surgeon's control than the former, for in mastoid cases the surgeon is more favourably circumstanced $(a)$ to remove the whole of the diseased products and tissues, $(b)$ to render the cavity more favourable to healing by removing ridges, and (c) to control cicatrisation by caustics and dressings. It is evident that the question of cicatrisation after even the most skilful operation on the sphenoidal sinus may be of great importance and that a cure may not have been effected, although for a considerable period there has been no discharge from the sinus.

Note-Although the subject of this paper is chronic suppuration of the sphenoidal sinus it is desirable that $I$ should give some additional facts relating to the three cases mentioned above, showing the extent of the area involved in the pathological process, in order that their character and significance may be more fully understood. In No. 1 there was on the left side (in addition to the ethmoidal and sphenoidal suppuration) suppuration of the frontal sinus and the antrum, both of which have been operated on from the outside. On the right side there are some small polypi and pus and it is not unlikely that some of the air-spaces will have to be dealt with. The nasal trouble in this case is believed to date from boyhood. In No. 2 there were on the right side nasal polypi and suppuration of the ethmoidal cells and sphenoidal sinus; the polypi and middle turbinate were removed, the ethmoidal cells were broken down and curetted, and the anterior wall of the sphenoidal sinus was broken down and the cavity curetted with an apparently satisfactory result. On this side the frontal sinus is to be opened. In No. 3 the left frontal sinus requires to be opened but for domestic reasons it has to be postponed.

Manchester.

Convalescent Home at Llanndudno.-The foundation-stone of a new convalescent home was laid at Llandudno on July 23rd by Lady Forester. The funds for the erection and endowment of the institution are derived from the estate of the late Lady Forester who bequeathed nearly $£ 750,000$ for the erection of hospitals and a convalescent home for the benefit of the poor of Shropshire and North Staffordshire.

\section{A whirror}

HOSPITAL PRACTICE,

BRITISH AND FOREIGN.

Nulla autem est alia pro certo noscendi ria, nisi quamplarimas ot norborum et dissectionum historias, tum aliorum tum proprias uorb., lib. iv., Pronemium.

\section{WESTMINSTER HOSPITAL.}

A CASE OF ANEURYSM OF THE SECOND AND THIRD PARTS OF THE LEFT SUBCLAVTAN ARTERY ; LIGATURE OF THE FIRST PART; RECURREN'T PULSATION; SIMULTANEOUS LIGATURE OF THE INFERIOR THYROID, VERTEBRAL, AND THIRD PART OF THE AXILLARY ARTERIES; RECOVERY.

(Under the care of Mr. Charles STonham, C.M.G.)

THE treatment of an aneurysm of the second or third part of the subclavian artery on the left side stands in rather a different position from that of an aneurysm of this vessel on the right side of the body, for on the right side there is no intrathoracic portion of the subclavian and ligature of the innominate artery is certainly a much more serious operation. On the left side, however, the first portion of the subclavian artery is much longer than on the right, and there is ample room for the application of a ligature internal to the origin of its branches. The following case is remarkable, not merely for the successful application of a ligature to the intrathoracic portion of the subclavian, but also for the subsequent ligation of several of its branches and of the axillary artery with an ultimately successful result. In estimating the prognosis of such operations no stress should be laid on the statistics of pre-antiseptic days, for sloughing of the sac and secondary bæmorrhage from the site of application of the ligature were the chief causes of failure and nowadays these are practically eliminated. We congratulate Mr. Stonham on the success of his treatment.

A man, aged 43 years, was admitted into Westminster Hospital on April 13th, 1899, in consequence of a swelling "in the root of the neck on the left side." The patient had contracted syphilis 14 years previously and 10 months before admission he had a gumma on the left calf, one on the inner side of the left thigh, and a third on the left forearm. In November, 1895, he was admitted into St. Peter's Hospital, Bristol, in consequence of "bronchitis and considerable hæmoptysis"; he was an in-patient 10 months, when he was discharged as suffering from phthisis and being incurable. He was then admitted into the st. George's Infirmary, Fulham-road, and improved considerably. On his discharge he resumed his work as a carpenter and worked regularly until he came to the hospital, although he was "troubled with his chest and a cough." $\mathrm{He}$ had also suffered from piles and right-sided sciatica. As regards his present illness, five months before admission the patient experienced an aching pain in the upper part of the left chest and noticed a swelling of about the size of a walnut at the root of the neck above the left clavicle. This swelling was at first very tender but the pain soon passed off and the patient put pressure on the swelling for two or three days, after which, according to him, it disappeared, but suddenly reappeared two or three days later. This swelling gradually increased in size, but although at first he occasionally suffered acute stabbing pain in the left chest and down the left arm this did not trouble him latterly and he continued his work until April 12th, 1899, the day before his admission.

On April 17th the patient was thin and had a worn expression. 'The chest was badly formed and its mobility was markedly defieient. The percussion note was somewhat impaired at the apex on both sides; there were no moist sounds or other abnormality; there was no expectoration. The heart was normal. The arteries were not rigid or particularly tortuous. The abdominal viscera were normal. The urine was of specific gravity 1016 , acid, and contained no albumin or sugar. The ends of the fingers were clubbed, especially on the left hand. There was a swelling in the left supra-clavicular region of about the size of a duck's egg 